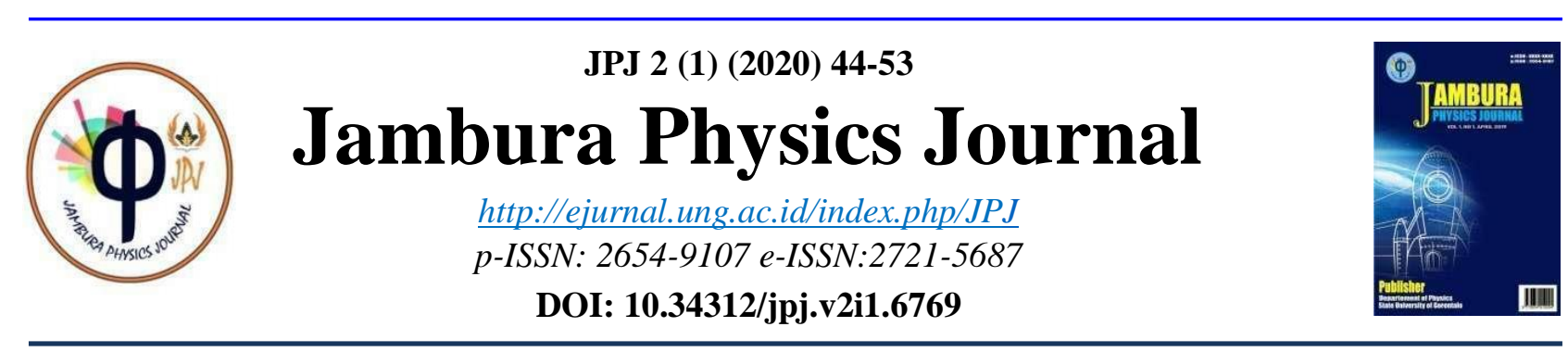

\title{
ANALISIS SEBARAN LAVA BANTAL WATUADEG YANG DIDUKUNG DATA VERTICAL ELECTRICAL SOUNDING (VES) DI LAPANGAN 'AGSTY' YOGYAKARTA
}

\author{
Dzakiya $N^{1 *}$, Aditya M.A.B ${ }^{2}$, Jayadi $\mathbf{H}^{3}$, Setiawan D.G.E ${ }^{4}$ \\ ${ }^{1,2}$ Institut Sains \&Teknologi AKPRIND, Jln Kalisahak No 28, Yogyakarta55221, Indonesia \\ ${ }^{3}$ Universitas Tadulako,Jln SoekarnoHatta KM 9 Palu, Sulawesi Tengah, 94118, Indonesia \\ ${ }^{4}$ Universitas NegeriGorontalo,Jl. Jend. Sudirman No. 6 Kota Gorontalo, 96128, Indonesia
}

Accepted: April 5 2020. Approved: April 10 2020. Published: April 302020

\begin{abstract}
ABSTRAK
Analisis sebaran lava bantal Watuadeg di Kecamatan Berbah DI Yogyakarta yang didukung data Vertical Electrical Sounding (VES )telah dilakukan.Keterdapatan lava bantal yang tersingkap di permukaan merupakan penanda bahwa dahulu daerah tersebut merupakan laut. Akibat proses geologi terutama tektonik mengakibatkan lava bantal tersebut terangkat kedaratan. Lava bantal yang belum tersingkap karena tertutup oleh soil (lapukan batuan) menjadi daya tarik tersendiri untuk dikaji. Persebaran lava bantal permukaan dominan mengalir dari sumbernya ke arah selatan dan menyebar ke tenggara serta dibatasi oleh Sungai Opak. Berdasarkan hasil analisis data VES, keberadan lava bantal di lokasi titik pengukuran berada di kedalaman $4 \mathrm{~m}$ dengan nilai resistivitas sebesar 1321,08 $\Omega \mathrm{m}$. Berdasarkan dari data geologi dan nilai resistivitas batuan tersebut dapat disimpulkan bahwa penyebaran lava bantal dominan ke arah selatan dari pusat erupsinya dengan sayap sebaran ke arah tenggara dan barat daya serta sebarannya masih ada di bawah permukaan.
\end{abstract}

Kata Kunci: berbah, lava bantal; vertical electrical sounding; watuadeg

\section{PENDAHULUAN}

Lava bantal terbentuk akibat dari lava hasil erupsi lelehan yang berkontak langsung dengan fluida lalu terjadi pembekuan yang cepat. Adanya kontak tersebut menyebabkan mineral-mineralnya tidak terbentuk dengan baik dan membentuk geometri mirip bantal, sehingga disebut lava bantal atau pillow lava (Mulyaningsih, 2016). Keberadaan batuan beku basaltik berstruktur lava bantal yang tersingkap di daerah Watuadeg Berbah sangat menarik untuk diteliti lebih lanjut. Hal ini menarik karena pembentukan lava tersebut terjadi di lingkungan air. Sifat lava di daerah penelitian cukup unik karena bersifat basaltis

*alamatkorespondensi

E-mail:dzakiya@akprind.ac.id 
berbeda dengan batuan beku di Pulau Jawa yang pada umumnya bersifat intermediet hingga asam.Interpretasi geologi menjelaskan aliran lava basal berstruktur bantal di Watuadeg Kali Opak mempunyai lebar singkapan antara 10-15 meter dengan panjang sekitar 50 meter. Tubuh lava seperti aliran getah atau berbentuk bantal guling dengan panjang aliran secata fisis berkisar 3-10 meter dan diameter 0,5-1 meter. Permukaan lava yang belum tererosi berwarna hitam mengkilap bertekstur glas menyerupai obsidian, dikenal sebagai kulit kaca (glassy skin) (Bronto, 2008)

Batas kontak dan geometri batuan berdasarkan pengamatan singkapan di permukaan, belum bisa secara pasti ditentukan sebagai kemenerusan di bawah permukaan. Arah persebaran dari lava bantal tersebut perlu diketahui agar didapatkan informasi tentang persebaran dari lava bantal tersebut. Hal inilah yang menjadi dasar dilakukan penelitian ini dengan tujuan pemetaan geologi permukaan yang didukung metode Vertical Electrical Sounding (VES) untuk mencari kemenerusan kedalaman dari lava bantal tersebut. Metode ini dilakukan di daerah yang di atasnya sudah tidak tersingkap lava bantal karena tertutup oleh soil, sehingga diperkirakan di bawah lokasi peneitian masih ada kemenerusan lava bantal tersebut pada kedalaman tertentu.Metode Vertical Electrical Sounding(VES) digunakan untuk menunjang data permukaan yang sudah ada. VES adalah metode yang menggambarkan secara vertikal data bawah permukaan secara satu dimensi (1D) meliputi keberadaan dan kedalaman lapisan batuan dengan mengukur nilai resistivitas batuan. Konfigurasi pada metode ini menggunakan konfigurasi Schlumberger yang peka terhadap kontras resistivitas batuan ke arah vertikal (Dzakiya, 2019).

\section{KAJIAN PUSTAKA}

Lava adalah cairan larutan magma pijar yang mengalir keluar dari dalam bumi melalui kawah gunung berapi atau melalui celah (patahan) yang kemudian membeku menjadi batuan yang bentuknya bermacam-macam. Proses keluarnya magma ke permukaan sangat berhubungan erat dengan proses tektonik yang ada di daerah tersebut. Magma dapat keluar di darat maupun di dalam laut. Magma yang keluar di dalam laut umumnya akan membentuk struktur pillow lava (lava bantal).Lava bantal adalah struktur lava yang biasanya terbentuk ketika lava muncul dari ventilasi vulkanik bawah laut atau gunung berapi subglacial atau aliran lava masuk laut. Lava ini juga dapat terbentuk ketika lava meletus di bawah es glasial tebal. Keterdapatannya yang tersingkap di permukaan merupakan penanda bahwa daerah tersebut dahulu merupakan laut. Akibat proses geologi 
terutama tektonik mengakibatkan lava bantal tersebut terangkat ke daratan hingga tersingkap di permukaan.

Bronto, dkk (2008) menyatakan bahwa aliran lava basal berstruktur bantal tersingkap di Kali Opak sebelah Barat Dusun Watuadeg, Sleman, Yogyakarta. Lava tersebut mempunyai panjang aliran sekitar 2-5 meter, diameter 0,5-1,0 meter dan membentuk kulit kaca di permukaannya. Arah aliran berubah secara bertahap dari $\mathrm{U} 70^{\circ} \mathrm{T}$ di bagian Utara menjadi U $120^{\circ} \mathrm{T}$ di tengah dan U $150^{\circ} \mathrm{T}$ di bagian Selatan. Kurang lebih 150 meter di sebelah Barat sungai terdapat sebuah bukit kecil setinggi 15 meter yang mempunyai komposisi sama dengan aliran lava bantal. Berdasarkan data tersebut diperkirakan bahwa bukit kecil itu merupakan sumber erupsi aliran lava bantal Watuadeg. Lava bantal itu ditindih oleh batuan klastika gunung api yang terdiri dari tuf, batu lapili dan breksi pumis yang merupakan bagian Formasi Semilir. Batuan klastika gunung api yang berada di dekat kontak mengandung fragmen basal piroksen berkomposisi sama dengan aliran lava bantal. Bersama dengan analisis data petrologi, vulkanologi dan umur radiometri menunjukkan bahwa aliran lava bantal Watuadeg secara tidak selaras ditindih oleh Formasi Semilir.

\section{METODOLOGI PENELITIAN}

\section{MetodeVertical Electrical Sounding (VES)}

Metode Vertical Electrical Sounding (VES) termasuk salah satu metode aktif yang menganalisis perubahan tahanan jenis di bawah permukaan bumi dengan mempelajari sifat-sifat kelistrikannya. Pengukuran metode VES biasanya menggunakan empat elektroda dengan dua elektroda berfungsi sebagai elektroda arus (C1 dan C2) serta dua elektroda yang berfungsi sebagai elektroda potensial (P1 dan P2). Prinsip dari metode ini adalah menginjeksikan arus DC melalui elektroda arus ke bawah permukaan bumi, sehingga

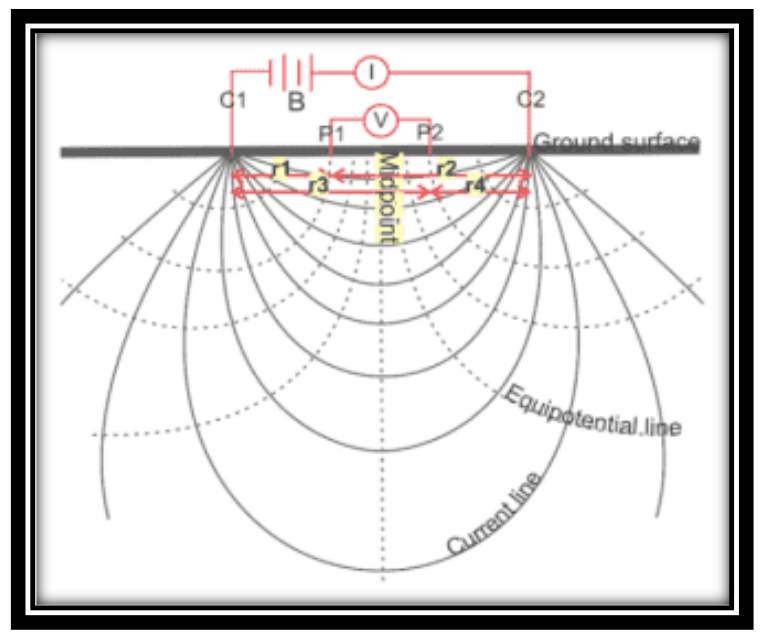

Gambar 1. Penjalaran arus dan bedapotensial pada suatu medium (modifikasi dari Todd, 2005) 
mengakibatkan beda potensial yang dapat diukur melalui elektroda arus. Parameter yang didapat dari pengukuran geolistrik ini berupa resistivitas atau nilai tahanan jenis. Nilai resistivitas tersebut menggambarkan karakteristik dari suatu batuan (Telford, 1990).

Sesuai dengan Hukum Ohm bahwa besar arus listrik (I) yang mengalir melalui sebuah penghantar atau konduktor akan selalu berbanding lurus dengan beda potensial (V) yang diterapkan kepadanya dan berbanding terbalik dengan resistansinya seperti pada persamaan berikut

$V=I R$

$R=\frac{1}{\sigma} \frac{l}{A}=\rho \frac{l}{A}$

$\rho=\frac{R A}{l}$

\section{Ananlisis Data}

Lokasi penelitian berada di Lapangan 'Agsty' sekitar Lava Bantal Watuadeg, Kecamatan Berbah, Kabupaten Sleman, Provinsi Yogyakarta. Luas daerah penelitian sekitar 1,5 km². Penelitian dilakukan selama satu bulan, yakni pada bulan Oktober 2016. Sedangkan untuk pengambilan data VES telah dilakukan sebelumnya pada 18 November 2015 .

Data primer dalam penelitian ini dibagi menjadi dua, yakni pemetaan batuan dan pengukuran data VES pada lokasi penelitian. Data-data yang diperoleh berupa data litologi, strik/dip, kontak batuan dan arah aliran lava. Kemudian dikorelasikan dengan pengukuran $V E S$ pada daerah penelitin yang permukaan berupa soil yang diperkirakan masih terdapat kemenerusan persebaran dari lava bantal tersebut. Setelah menentukan lokasi pengukuran VES kemudian dilakukan dengan instumen geolistrik dengan bentangan sepanjang 200 metersesuai diagram alirGambar 1. Persebaran lava basalt ini dicari dengan melakukan pengukuran di bagian sisi Barat untuk mengetahui kedalaman lava basalt danpersebarannya.

Data-data yang telah dikumpulkan selanjutnya diolah.Data pemetaan dibuat peta gologi dareah penelitian yang menjelaskan tentang persebaran lava bantal litologi di permukaan. Petainimembantumengetahui area masing-masing litologi dan umur relatif batuan penampang atau sayatan dua dimensi (2D) bawah permukaan.Sedangkan untuk data-data hasil pengukuran geofisika akan diolah menggunakan software PROGRES. Hasilnya berupa nilai resistivitas bawah permukaan.Kedua data tersebut dikorelasikan, sehingga 


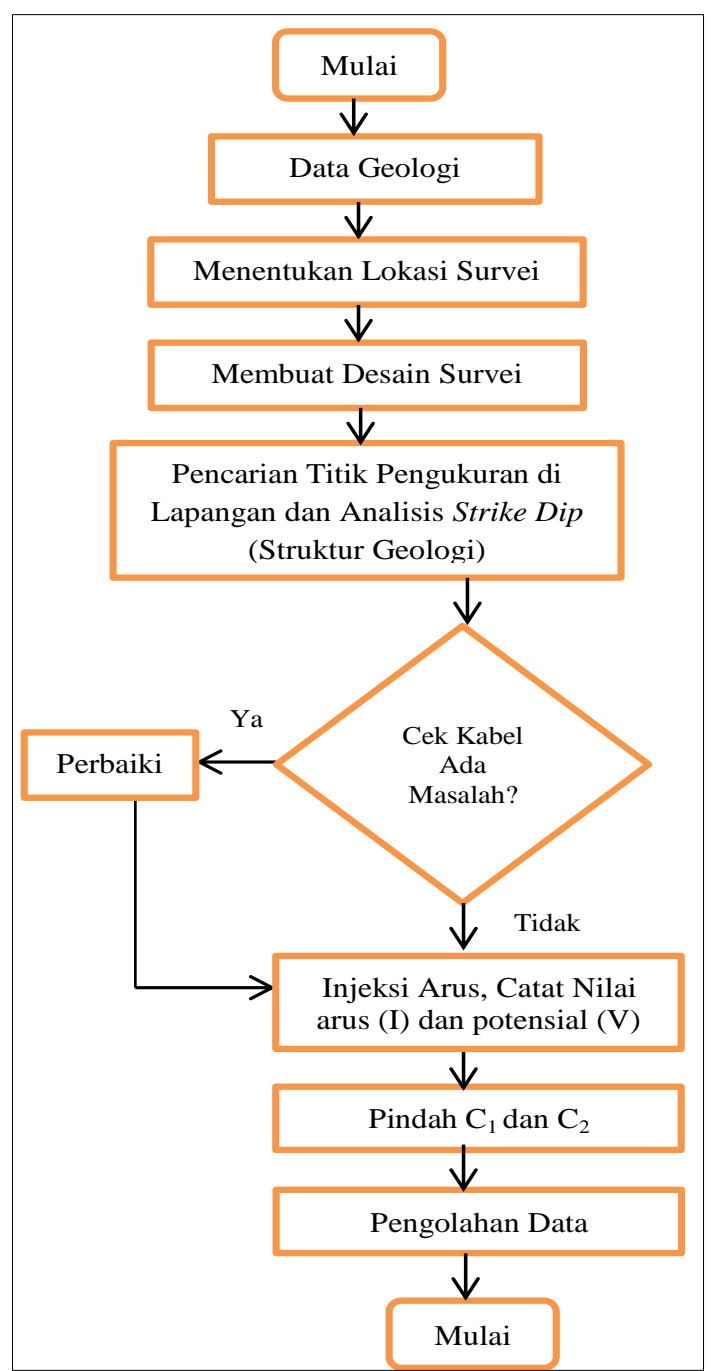

Gambar 2. Diagram Alir Metode Vertical Electrical Sounding (VES)

didapatkan hasil yang dapat untuk membantu menentukan arah persebaran lava bantal pada daerah penelitian. Adapun alur pengolahan data dapat dlihat pada Gambar 2 dan 3.

Secara fisiografis daerah Watu Adeg merupakan perbukitan kecil-kecil dengan ketinggian kurang dari 100 meter yang di sekitarnya berupa dataran pesawahan subur. Perbukitan kecil tersebut tersusun oleh batuan gunung api Tersier yang menjadi penyusun sebagian Pegunungan Selatan.Lava bantal yang terdapat diWatu Adeg Kecamatan Berbah, Kab Sleman, DI Yogyakarta ini hanya tersingkap di tepi Barat Sungai Opak memanjang dari Utara ke Selatan sepajang \pm 500 meter. Sedangkan pada bagian Timur Sungai Opak keberadaannya tidak ditemukan lagi. Bagian Barat dari singkapan lava bantal tersebut terdapat bukit yang sangat subur, sehingga oleh masyarakat setempat dijadikan pemukiman sekaligus ladang. Hal tersebut menunjukkan bahwa kemungkinan terdapat lava bantal pada bagian Barat singkapan di bawah permukaan. 


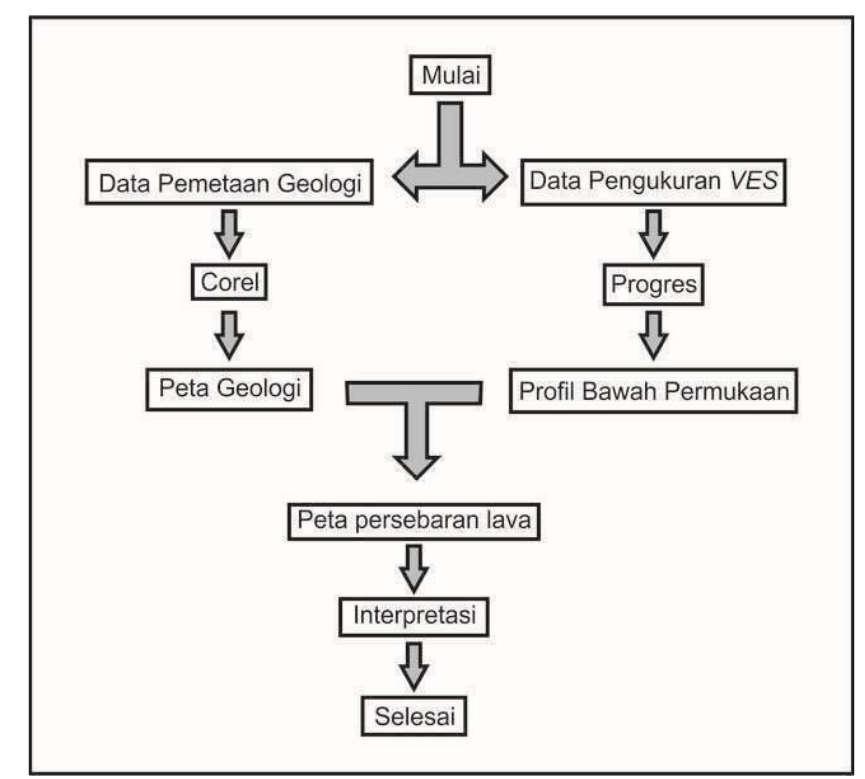

Gambar 3. Diagram Alir Pengolahan Data

\section{HASIL DAN PEMBAHASAN}

Singkapan batuan di daerah penelitian termasuk satuan lava basalt dengan warna hitam segar, warna lapuk kuning kecoklatan dan memiliki struktur bantal. Derajat kristalisasi hipokristalin, granularitas afanitik, bentuk kristal subhedral-anhedral. Hubungan antar kristal equigranular memiliki komposisi terdiri dari mineral piroksen, gelas dan plagioklas. Satuan ini ditemukan di LP 2, 3, 6, 8, 9 dan 11. Bagian tengah menempati $\pm 19 \%$ daerah penelitian.

Pengukuran arah aliran dari lava bantal dilakukan pada LP 2 dan 3 yang didapatkan arah azimut aliran $\mathrm{N} 72^{\circ} \mathrm{E}$ dan azimut $\mathrm{N} 24^{\circ} \mathrm{E}$ di LP 2 seperti pada Gambar 4. Azimut aliran lava $\mathrm{N} 110^{\circ} \mathrm{E}$ dan $\mathrm{N} 87^{\circ} \mathrm{E}$ di LP 3 terlihat seperti pada Gambar 5. Setelah dibuat peta geologi daerah penelitian terlihat bahwa aliran lava basalt yang terdapat pada lokasi penelitian memiliki arah umum Timur Tenggara seperti pada Gambar 4 dan Gambar 5.

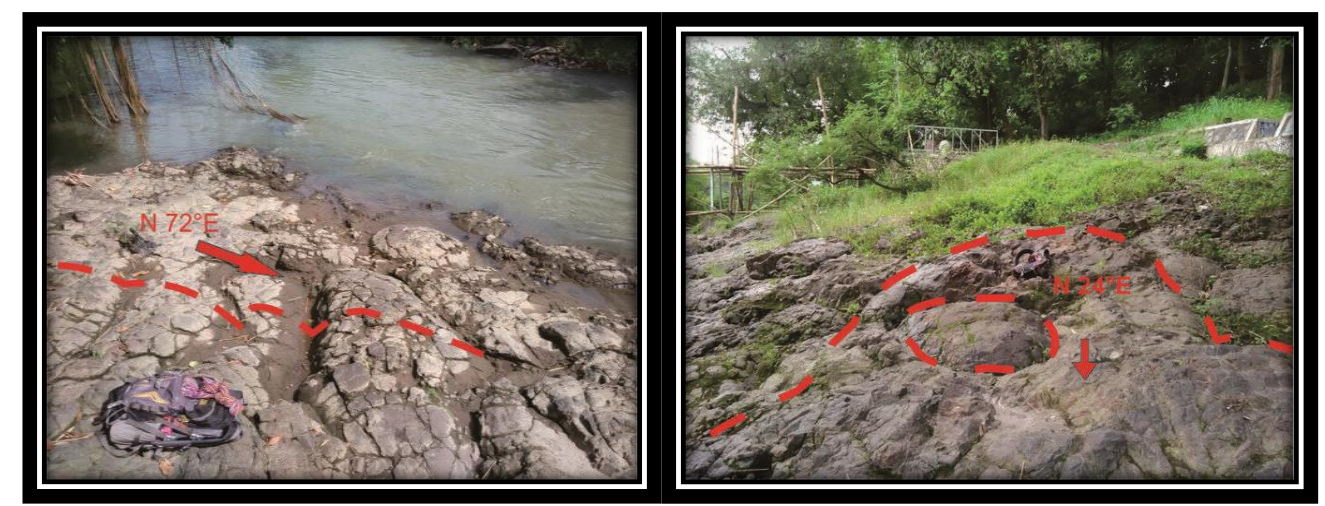

Gambar 4. Satuan lava bantal pada LP 2 dengan arah aliran $N 72^{\circ} \mathrm{E}$ dan $\mathrm{N} 24^{\circ} \mathrm{E}$ 


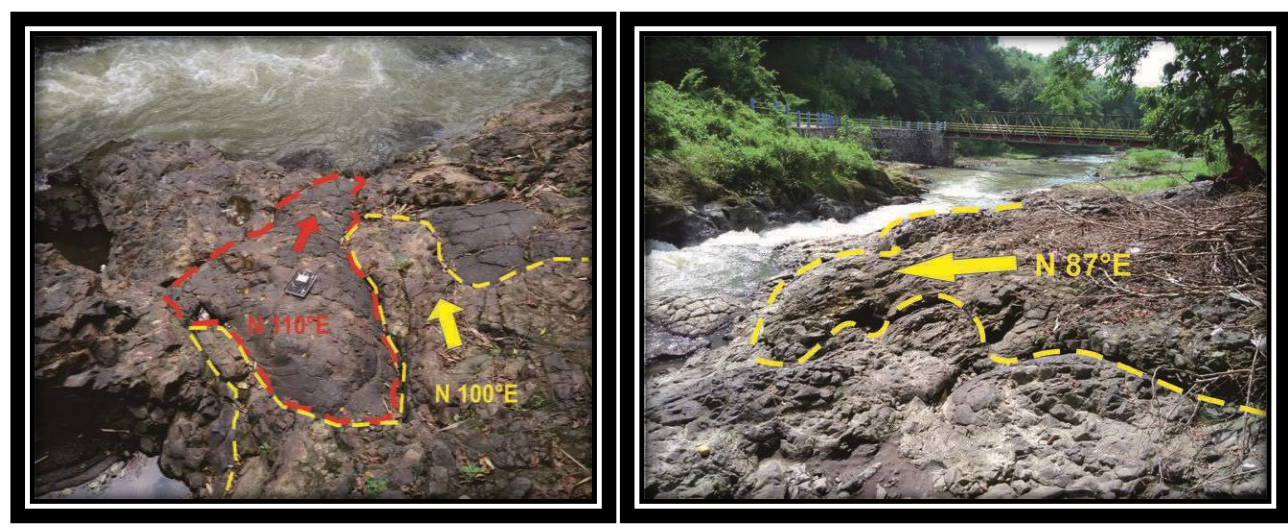

\section{Gambar 5. Arah sebaran lava bantal pada daerah penelitian di tepian kali opak}

Pengukuran geolistrik titik VES dilakukan pada 18 November 2015 di daerah persawahan dengan ketinggian 92 mdpl dan panjang bentangan 200 meter ke sisi Timur dan Barat dari titik pengukuran. Pengukuran mendapatkan data seperti yang ditampilkan pada Tabel 1. Penggolahan data VES menggunakan software PROGRESS yang hasil

Tabel 1. Hasil data pengukurangeolistrikmetode VES

\begin{tabular}{rrrrrrrr}
\hline No & $\mathrm{AB} / 2$ & $\mathrm{MN} / 2$ & \multicolumn{1}{c}{$\mathrm{K}$} & $\mathrm{I}(\mathrm{mA})$ & $\mathrm{V}(\mathrm{mV})$ & $\mathrm{R}(\Omega)$ & $\mathrm{Rho}(\Omega \mathrm{m})$ \\
\hline 1 & 1 & 0,5 & 2,35 & 4,99 & 169,1 & 33,84 & 79,70 \\
2 & 1,5 & 0,5 & 6,28 & 4,99 & 97,41 & 19,49 & 122,44 \\
3 & 2 & 0,5 & 11,77 & 4,99 & 58,81 & 11,77 & 138,60 \\
4 & 3 & 0,5 & 27,47 & 4,99 & 30,53 & 6,11 & 167,89 \\
5 & 4 & 0,5 & 49,45 & 4,99 & 18,85 & 3,77 & 186,59 \\
6 & 5 & 0,5 & 77,71 & 4,99 & 13,65 & 2,73 & 212,33 \\
7 & 6 & 0,5 & 112,25 & 4,99 & 10,4 & 2,08 & 233,67 \\
8 & 7 & 0,5 & 153,07 & 4,99 & 8,15 & 1,63 & 249,83 \\
9 & 8 & 0,5 & 200,17 & 4,99 & 6,55 & 1,31 & 262,79 \\
10 & 10 & 0,5 & 313,21 & 4,99 & 4,53 & 0,90 & 284,18 \\
11 & 12 & 0,5 & 451,37 & 4,99 & 3,31 & 0,66 & 299,59 \\
12 & 15 & 0,5 & 705,71 & 4,99 & 2,21 & 0,44 & 312,88 \\
13 & 20 & 0,5 & 1255,21 & 4,99 & 1,17 & 0,23 & 296,21 \\
14 & 20 & 5 & 117,75 & 4,99 & 11,14 & 2,22 & 262,58 \\
15 & 30 & 5 & 274,75 & 4,99 & 3,69 & 0,73 & 203,03 \\
16 & 40 & 5 & 494,55 & 4,99 & 1,56 & 0,31 & 154,42 \\
17 & 50 & 5 & 777,15 & 9,99 & 1,34 & 0,13 & 104,56 \\
18 & 60 & 5 & 1122,55 & 9,99 & 0,73 & 0,07 & 81,97 \\
19 & 75 & 5 & 1758,4 & 19,99 & 0,68 & 0,03 & 60,14 \\
20 & 75 & 20 & 410,16 & 19,99 & 2,77 & 0,13 & 56,83 \\
21 & 100 & 20 & 753,6 & 19,99 & 0,96 & 0,04 & 36,48 \\
22 & 125 & 20 & 1195,16 & 19,99 & 0,39 & 0,01 & 23,84 \\
23 & 150 & 20 & 1734,85 & 19,99 & 0,22 & 0,01 & 19,08 \\
24 & 200 & 20 & 3108,6 & 19,99 & 0,10 & 0,005 & 15,71 \\
\hline & & & & & & &
\end{tabular}


akhirnya berupa nilai resitivitas dan kedalaman semu batuan (phseudodepht), sehingga jenis batuan dapat diinterpretasi secara geologi.

Gambar 6 merupakan hasil pengolahan data VES menggunakan software PROGRESS. Data yang dibaca merupakan data resistivity log yang berupa nilai resitivitas batuan sebagai fungsi kedalaman. Hasil pengolaan data klasifikasi nilai resitivitas dapat diketahui bahwa hasil pengukuran VES diinterpretasi secara geologi masih terdapat kemenerusan persebaran lava bantal di arah barat daya dari makam. Selain itu diinterpretasi jenis-jenis litologi di bawah titik VES yang hasilnya dapat dilihat pada Gambar 7.

Bedasarkan data pemetaan geologi dan pengukuran VES dapat di simpulkan bahwa arah umum persebaran lava bantal berarah ke Selatan yang melebar ke bagian Tenggara dan Baratdaya dari letak persebaran lava bantal dan pengukuran titik VES (sekitar makam) sebagai pusat erupsi lava bantal yang dapat di lihat pada Gambar 5. Seperti penelitian Nurcholis dkk (2013) di tepian Sungai Opak dibagian Selatan dari singgkapan lava bantal tersebut. Penelitian tersebut menyimpulkan bahwa persebaran lava bantal terdapat bada bagian Barat Sungai Opak.

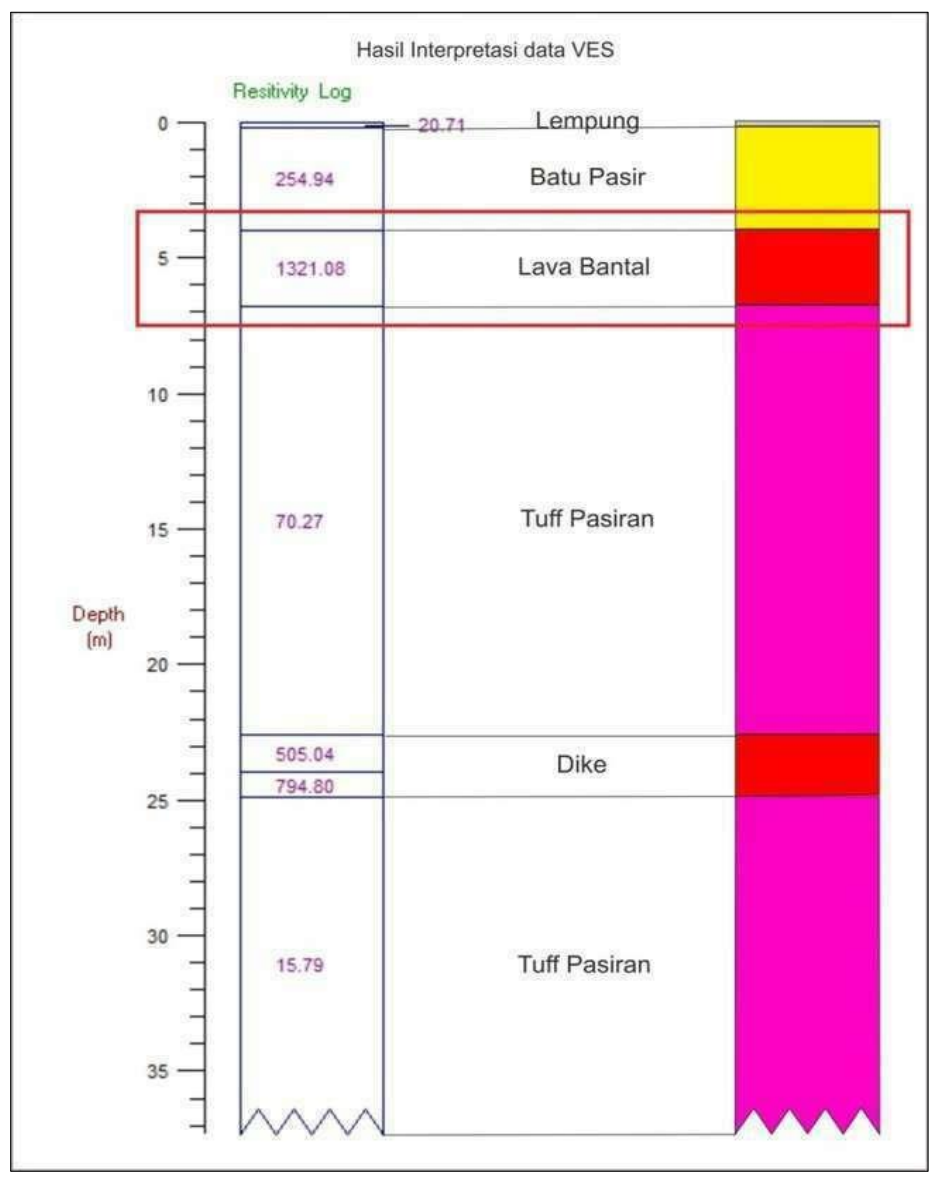

Gambar 6. Interpretasi litologi di bawah permukaan berdasarkan pengukuran metode $V E S$ 
Tabel 2. Interpretasi litologi berdasarkan nilai resistivitas

\begin{tabular}{ccccc}
\hline Lapisan & Rho (ohm.m) & $\begin{array}{c}\text { Kedalaman } \\
(\mathrm{m})\end{array}$ & $\begin{array}{c}\text { Ketebalan } \\
(\mathrm{m})\end{array}$ & $\begin{array}{c}\text { Interpretasi } \\
\text { litologi }\end{array}$ \\
\hline 1 & 20,71 & $0-0,2$ & 0,2 & Lempung \\
2 & 254,94 & $0.2-4$ & 3,8 & Batu pasir \\
3 & 1321,08 & $4-7$ & 3 & Lava Bantal \\
4 & 70,27 & $7-22,5$ & 15,5 & Tuff Pasiran \\
5 & 505,04 & $22,5-24$ & 1,5 & Dike \\
6 & 794,80 & $24-25$ & 1 & Dike \\
7 & 15,79 & $25-\ldots$ & - & Tuff Pasiran \\
\hline
\end{tabular}

Hasil pengolahan data lapangan dengan software PROGRES 3.0 di dapatkan model log resistivity. Data tersebut dikorelasikan dengan data geologi permukaan ditampilkan pada Gambar 7. Adanya tujuh lapisan batuan di kedalaman hingga 35 meter di bawah permukaan. Berdasarkan Interpertasi bawah permukaan didapatkan lava bantal pada lapisan litologi ke tiga yang telah ditunjukan oleh kotak berarna merah. Masing-masing lapisan diinterpretasikan pada Tabel 2.

Berdasarkan hasil pengukuran VES yang telah lakukan didapatkan batuan beku pada kedalaman 4 meter yang diperkirakan keterdapatan lava bantal dari tepi barat sungai opak menerus ke Barat dan terdapat dua litologi batuan beku yang dipisahkan oleh batu pasir yang cukup tebal, sehingga diperkirakan batuan beku pada lapisan awal adalah lava bantal

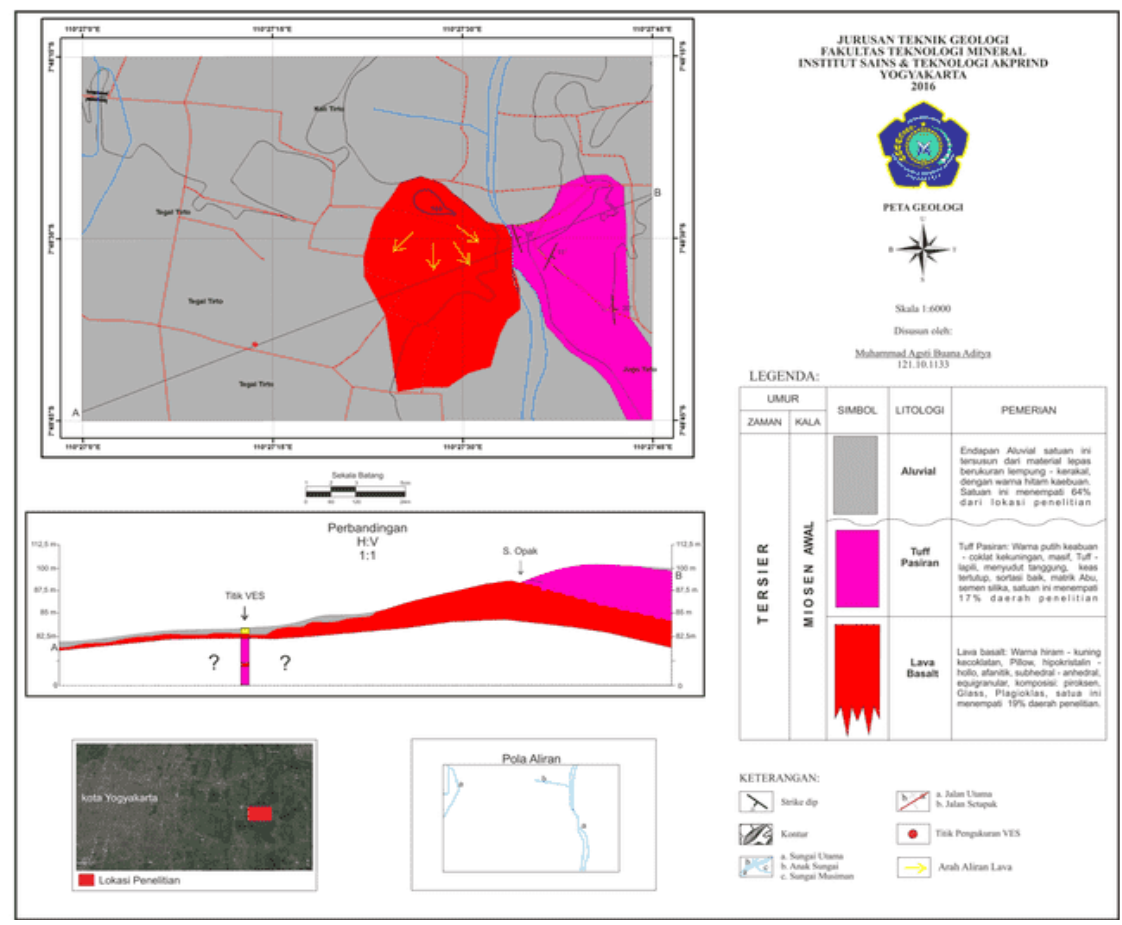

Gambar 7. Peta geologi sebaran lava bantal 
dan batu beku yang kedua adalah dike. Diinterpretasikan bahwa tuff pasiran Formasi Semilir telah ada terlebih dahulu yang dipotong oleh dike kemudian tutupi oleh lava bantal. Persebaran lava bantal dominan ke Selatan dari pusat erupsinya, dengan sayap sebaran kearah tenggara dan Barat dayaseperti pada Gambar 7.

\section{KESIMPULAN}

Korelasi data pemetaan di permukaan dan data pengukuran VES di Lapangan "Agsty" sekitar Lava Bantal Watuadeg dihasilkan bahwa penyebaran lava bantal dominan mengalir dari pusat erupsinya ke Selatan dengan sayap menyebar ke Tenggara dan Baratdaya dengan Sungai Opak sebagai batas kontak persebaran lava bantal. Lava bantal yang berupa litologi basalt memiliki nilai resistivitas sekitar $1321,08 \Omega \mathrm{m}$ berada pada sisi sebelah timur yang diperkirakan berada di kedalaman 4 meter di bawah permukaansedangkan di permukaannya tertutup soil tebal sehingga tidak tersingkap.

\section{REFERENSI}

Mulyaningsih S., Sampurno., Zaim Y., Puradimaja D J., Bronto S., \& Siregar D A. (2016). Perkembangan Geologi Pada Kuarter Awal Sampai Masa Sejarah di Dataran Yogyakarta, Jurnal Geologi Indonesia.

Bronto S, Mulyaningsih S, Hartono G \& Astuti B. (2008). Gunung Api purba Watuadeg: Sumber erupsi dan posisi stratigrafi, Jurnal Geoogi Indonesia.

Todd, D.K., and Mays, L.W., Groundwater Hydrology, 3th ed, Argosy Publishing, pp. 35$85,2005$.

Dzakiya, N., Sastrawan, F.D., Laksmana, R.B., Amara, M.M.SA, 2019, Identification of lithology properties of groundwater by using resistivity method in Girimulyo, Kulon Progo, Yogyakarta, Journal of Physics: Conf. Series, 1153 (012014), pp. 1-7.

Telford, W. M., Geldart, L. P., \& Sheriff, R. E. (1990). Applied Geophysics. New York: Cambridge University Press. 